\title{
The Growth Response of Rats to Purified Diets
}

\author{
By ALICE M. COPPING, PATRICIA J. CROWE AND VANDA R. G. POND \\ Lister Institute of Preventive Medicine, London, S.W. I
}

(Received 10 August 1950)

In attempts to design a complete purified diet some observations were made on the rates of weight increase in rats receiving simple basal diets with various supplements. A recent review by Dunn, Murphy \& Rockland (I947) on the optimal growth rate of the rat increased our interest in the studies of Zucker, Hall, Young \& Zucker $\left(194^{1} a-c\right)$ on the relation of weight to age in the rat and, although the numbers of rats in our groups were small, it appeared to be worth recording their growth performances for the information of others who may be concerned with various problems involved.

\section{EXPERIMENTAL}

Animals. 'The animals were rats of the black-and-white Lister Institute stock taken at weaning, aged $21-23$ days and weighing $35-45 \mathrm{~g}$. They were placed immediately in open-grid cages of the type used for experiments on vitamins of the $B$ complex and were given experimental diets, with various supplements, from 28 days of age. During the Ist week there were four animals in a cage; thereafter they were housed separately. Litters of eight rats were used, and in all experiments diets, doses and supplements were distributed in such a way as to give the fullest possible litter-mate comparison with due regard to sex.

Diets. The diets used in all tests were based on the following formula expressed as percentages: casein 20 , sucrose or maize starch 60 , hardened arachis oil 12 , lard 3 , salt mixture (McCollum 185) 5. When sucrose was the source of carbohydrate the diets were given dry and uncooked; when starch was used the dry ingredients were mixed with an equal weight of water and steamed until the starch was completely cooked, in order to obviate refection (Fridericia, Freudenthal, Gudjonnsson, Johansen \& Schoubye, 1927). The cooked diets are particularly convenient because they can be given as solid blocks that are not easily wasted in open-grid cages. In the earlier tests vitamins $A$ and $D$ were given as $0.02 \mathrm{ml}$. cod-liver oil daily; later Adexolin (Glaxo Laboratories Ltd.) was diluted with arachis oil so that one drop once a week provided r 20 i.u. vitamin $A$ and 20 i.u. vitamin D. In these tests vitamin $E$ was given also as a weekly dose of $\mathrm{r} \mathrm{mg}$. $\alpha$-tocopherol acetate dissolved in arachis oil and always at least $48 \mathrm{hr}$. after the dose of vitamins $A$ and $D$.

The members of the vitamin B complex now obtainable as pure crystalline substances were given as a solution containing in $\mathrm{I} \mathrm{ml}$.:

$\begin{array}{lrlr}\text { Vitamin } B_{1} & \text { ro } \mu \mathrm{g} . & \text { Riboflavin } & 40 \mu \mathrm{g} . \\ \text { Vitamin } B_{6} & 10 \mu \mathrm{g} . & \text { Nicotinic acid } & \text { I mg. } \\ \text { Pantothenic acid } & \text { roo } \mu \mathrm{g} . & \text { Biotin } & 0.2 \mu \mathrm{g} . \\ \text { p-Aminobenzoic acid } & \text { I } \mathrm{mg} . & \text { Folic acid } & 2 \mu \mathrm{g} . \\ \text { Inositol } & \text { I mg. } & \text { Choline } & 3 \mathrm{mg} .\end{array}$


A daily dose of $\mathrm{I} \mathrm{ml}$. of this solution provided an adequate supply of all the B-vitamins, since no beneficial effect was observed if it was increased.

The aqueous liver extracts used included a crude commercial extract of whole liver and various filtrates obtained after whole-liver extracts had been treated with charcoal. All the extracts were supplied by Glaxo Laboratories Ltd. with data as to the equivalence of the extracts in terms of the weight of liver from which they had been made. 'The daily doses of liver extract were material from $6 \mathrm{~g}$. original liver.

Three different types of casein were used. They were an alkaline caseinate (of the 'light white casein' type) from Glaxo Laboratories Ltd., a highly purified 'Labco' casein from the Borden Company, U.S.A., and a casein prepared in New Zealand by acid washing but without extraction by organic solvents.

To some animals a diet containing $15 \%$ yeast was given. The yeast was a commercial dried brewer's yeast and replaced $15 \%$ of starch in the diet. In all tests some rats were given the normal stock diet, which consisted of a mixture of full-cream dried milk, bread, whole wheat, bran, wheat germ, oat flakes, fishmeal and meat. These animals were kept in separate cages and otherwise treated exactly like those having the synthetic diets.

Experimental arrangement. For the final experiments the numbers of rats, the diets and the doses in the different groups were:

A. Sixteen rats on Labco casein diet and solution of B-vitamins.

B. Sixteen rats on Labco casein diet, solution of B-vitamins and a charcoal filtrate from liver.

C. Sixteen rats on 'light white casein' diet and solution of B-vitamins.

D. Sixteen rats on 'light white casein' diet, solution of B-vitamins and charcoal filtrate from liver.

E. Eight rats on 'light white casein' diet containing $15 \%$ dried yeast.

F. Eight rats on New Zealand casein diet and solution of B-vitamins.

G. Eight rats on New Zealand casein diet, solution of B-vitamins and charcoal filtrate from liver.

H. Fourteen rats on normal stock diet.

\section{RESULTS}

Preliminary tests indicated that a satisfactory weight increase could be obtained in rats on a diet of highly purified materials with all the known vitamins in crystalline form, but that the weight increase was not as great as that obtained in comparable animals receiving a liver extract. It was established also that a charcoal filtrate from whole iver supplemented with the solution of B-vitamins gave the same weight increases as crude liver extracts. In all subsequent experiments, therefore, the charcoal filtrate was used, being more easily obtainable. These tests suggested that the liver extracts contained some factor or factors different from any of the individual vitamins used.

The results of the final tests with eight different groups of rats are summarized in Table I, showing the average weekly weight increases of the males and females for a period of 14 weeks. The growth performance of the males was, as usual, always superior to that of the females. The differences between groups with and without liver 
Table I. Average weekly growth responses of rats during 14 weeks on different diets

\begin{tabular}{|c|c|c|c|c|}
\hline \multirow[b]{2}{*}{ Group } & & \multirow{2}{*}{$\begin{array}{c}\text { Mean weekly } \\
\text { weight increase } \\
\text { with its } \\
\text { standard error } \\
\text { (g.) }\end{array}$} \\
\hline & Diet & No. & Sex & \\
\hline A & $\begin{array}{l}\text { Labco casein and solution of } \\
\text { B-vitamins }\end{array}$ & $\begin{array}{l}8 \\
8\end{array}$ & $\begin{array}{l}\delta \\
\$ \\
q\end{array}$ & $\begin{array}{l}16 \cdot 4 \pm 0.4 \\
11 \cdot 6 \pm 0.4\end{array}$ \\
\hline $\mathbf{B}$ & $\begin{array}{l}\text { Labco casein, solution of B-vitamins } \\
\text { and liver extract }\end{array}$ & $\begin{array}{l}7 \\
9\end{array}$ & $\begin{array}{l}0 \\
q \\
q\end{array}$ & $\begin{array}{l}17 \cdot 7 \pm 0 \cdot 7 \\
11 \cdot 7 \pm 0 \cdot 4\end{array}$ \\
\hline c & $\begin{array}{l}\text { Light white casein and solution } \\
\text { of B-vitamins }\end{array}$ & $\begin{array}{l}8 \\
8\end{array}$ & $\begin{array}{l}0 \\
0 \\
+\end{array}$ & $\begin{array}{l}16.3 \pm 0.1 \\
10.7 \pm 0.4\end{array}$ \\
\hline $\mathrm{D}$ & $\begin{array}{l}\text { Light white casein, solution of } \\
\text { B-vitamins and liver extract }\end{array}$ & $\begin{array}{l}7 \\
9\end{array}$ & $\begin{array}{l}0 \\
\$ \\
q\end{array}$ & $\begin{array}{l}17 \cdot 5 \pm 1 \cdot 0 \\
11.8 \pm 0.6\end{array}$ \\
\hline $\mathbf{E}$ & Light white casein and $15 \%$ yeast & $\begin{array}{l}4 \\
4\end{array}$ & $\begin{array}{l}6 \\
q\end{array}$ & $\begin{array}{l}18 \cdot 8 \pm 0.9 \\
10 \cdot 7 \pm 0.4\end{array}$ \\
\hline $\mathbf{F}$ & $\begin{array}{l}\text { New Zealand casein and solution } \\
\text { of B-vitamins }\end{array}$ & $\begin{array}{l}4 \\
4\end{array}$ & $\begin{array}{l}0 \\
q\end{array}$ & $\begin{array}{l}16.2 \pm 0.5 \\
11.5 \pm 0.3\end{array}$ \\
\hline $\mathbf{G}$ & $\begin{array}{l}\text { New Zealand casein, solution of } \\
\text { B-vitamins and liver extract }\end{array}$ & $\begin{array}{l}4 \\
4\end{array}$ & $\begin{array}{l}0 \\
0 \\
+\end{array}$ & $\begin{array}{l}18 \cdot 5 \pm 0.8 \\
12.3 \pm 0.7\end{array}$ \\
\hline $\mathbf{H}$ & Normal stock diet & $\begin{array}{l}6 \\
8\end{array}$ & $\begin{array}{l}3 \\
+\end{array}$ & $\begin{array}{l}21 \cdot 8 \pm 0.5 \\
13.6 \pm 0.7\end{array}$ \\
\hline
\end{tabular}

extract and between those with purified and stock diets were examined statistically by the $t$ test and were mostly not significant. This was probably due to the small numbers in each group. No group having purified diet even with the supplement of liver extract showed mean weight increases equal to those of rats having the normal stock diet. The close approximation of the growth of the animals in all groups, except those on stock diet, is shown in Fig. $\mathrm{r} a, b$, which are the curves of mean weight increase plotted against age in weeks.

\section{DISCUSSION}

During 1941 Zucker et al. (1941 $a-c$ ) published a series of papers on the growth of the rat, and their observations on the relation of weight to age in rats receiving adequate 'normal' diets led them to state that growth might be represented by a straight line when the logarithm of the weight was plotted against the logarithm of the age in days from the time of conception up to 28 days after birth, and that thereafter a departure from this straight line occurred and the linear relationship was then obtained by plotting the logarithm of the weight against the reciprocal of the time. The formula on which this line was based expresses the relationship of growth rate to age and can be expressed algebraically as

$$
\log W=-k / t+\log A,
$$

$W$ being the weight at time $t, A$ the maximum weight approached asymptotically in the adult animal, $\log A$ the intercept of the straight line and $k$ the slope of the line, which characterizes growth rate. The value for $k$ was obtained from the formula

$$
k=\frac{\log W_{2}-\log W_{1}}{\mathrm{I} / t_{1}-\mathrm{I} / t_{2}}
$$


From Zucker's studies of his own rat colony and from calculations made on data from others a series of lines was obtained, each slope being characteristic of a particular colony. The slopes of the lines for females were always flatter than those for males and the values for $k$ tended to be more variable for females.

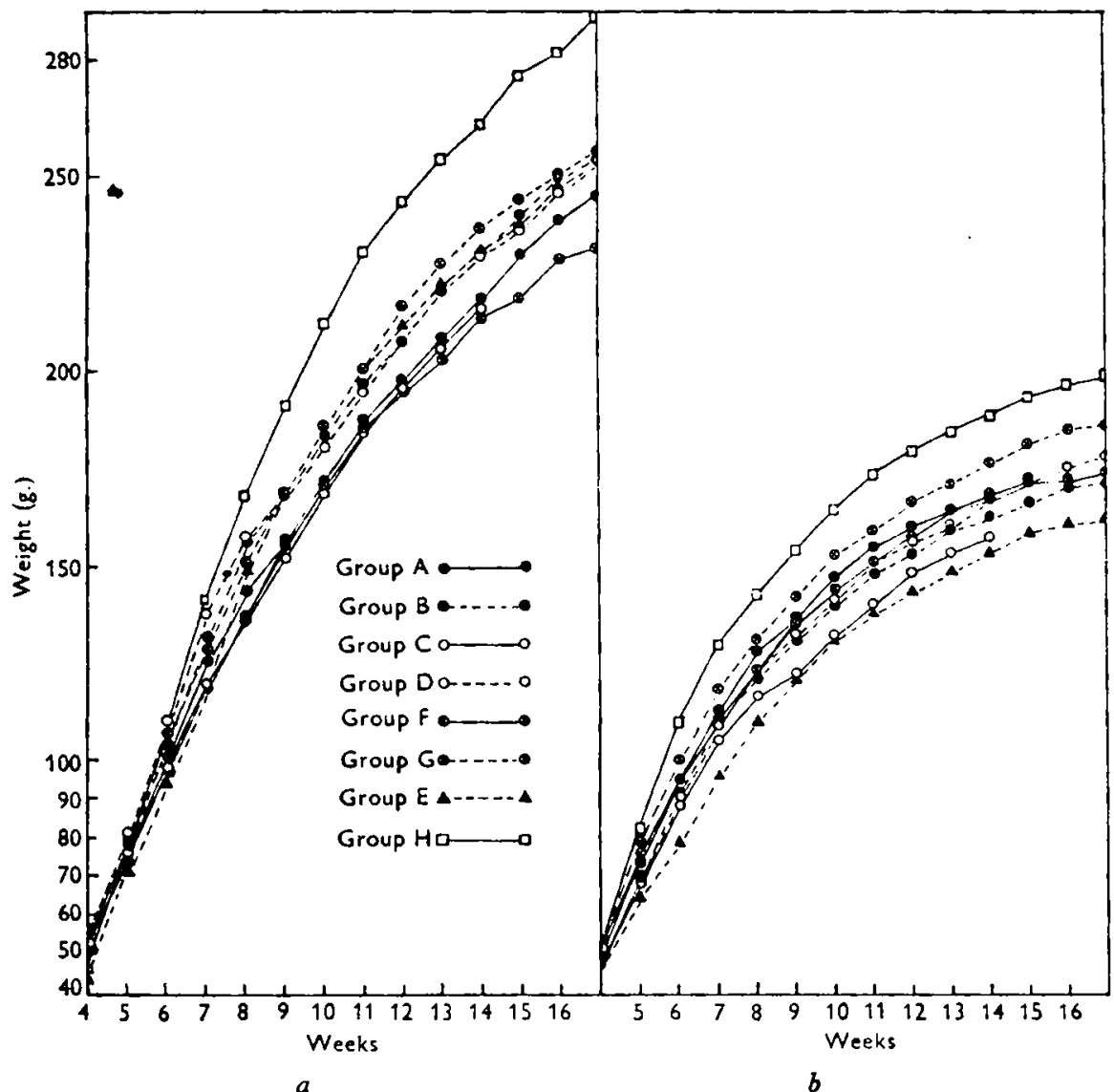

Fig. I $a$. Curves showing the relation between age in weeks and mean body-weight in $\mathrm{g}$. of male rats on various diets.

Fig. I $b$. Curves showing the relation between age in weeks and mean body-weight in g. of female rats on various diets.

Zucker \& Zucker (1943) showed that departure from the straight line expressed by $\log W=-k / t+\log A$ indicated inadequacy in the diet.

In view of these reports it seemed useful to apply Zucker's method of calculation to the results of the growth tests with the synthetic diets, although the numbers of animals in our groups were small in comparison with those used by Zucker. The curves obtained by his formula are set out in Figs. 2 and 3 ; it will be seen that, in spite of the limitations of the tests, reasonably straight lines are obtained at first for all the different diets. After some weeks the points tend to fall away from the lines in those groups in which the rats had the diet containing $15 \%$ yeast or the stock diet. In these two sets 

of curves, both for males and females, it seems that there is a deflexion of the line at about I I weeks of age. A similar deflexion of the growth curve was found by Dunn et al. (1947) in rats of the Long-Evans strain receiving the diet of Anderson \& Smith (1932), which was rich in protein. This suggests that the diet containing $15 \%$ yeast and the normal stock diet probably provided more than adequate protein which might be expected, in accordance with the findings of Anderson \& Smith (1932) and Dunn et al. (1947), to hasten early growth and to cause a subsequent decline in growth rate.

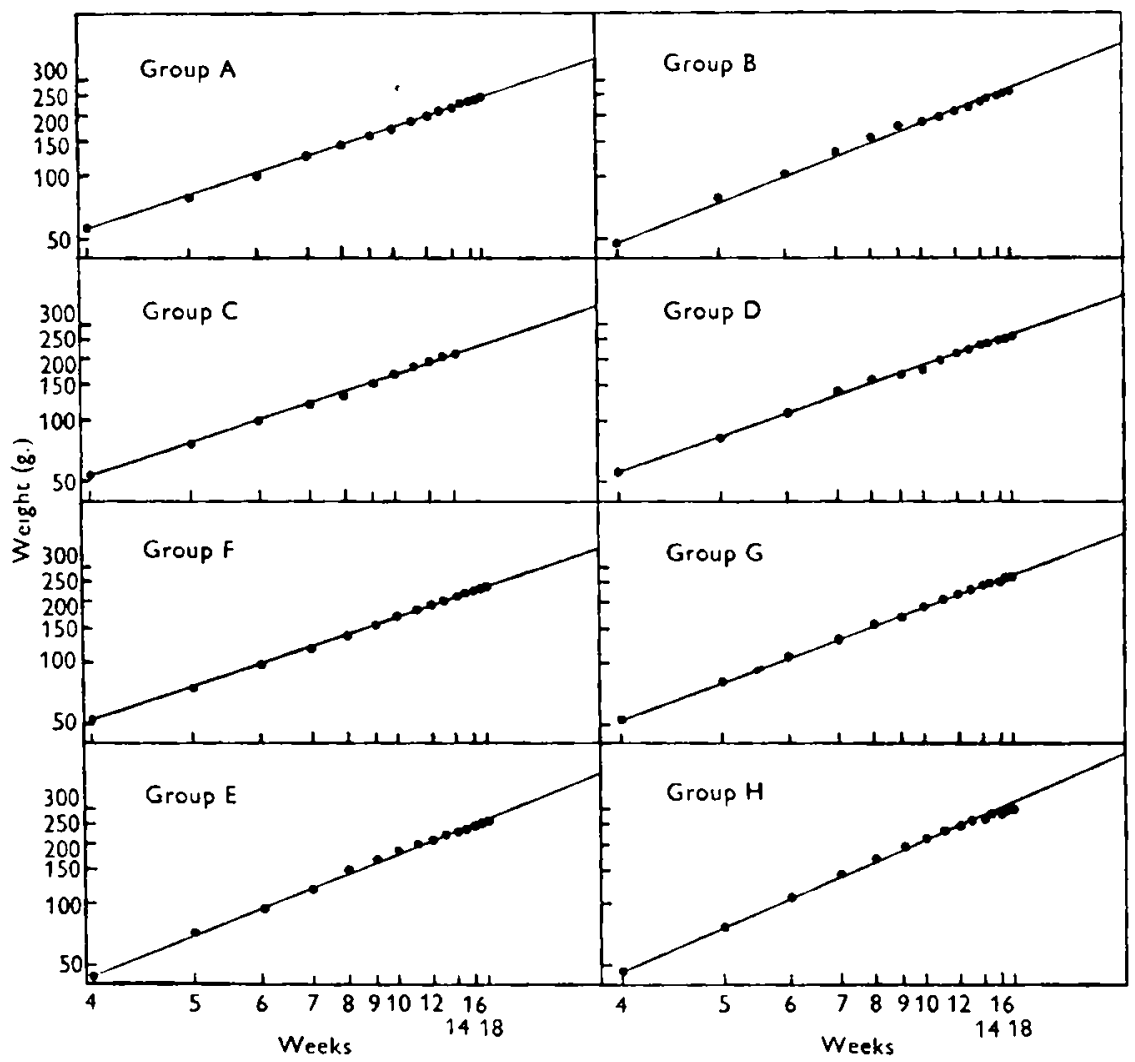

Fig. 2. Curves showing the relation between the reciprocal of the age in weeks and the logarithm of the mean body-weight in $\mathrm{g}$. of male rats on various diets.

This may be contrasted with observations of Zucker \& Zucker (1943) on the deflexion of the growth curve in the early stages of growth with a diet containing inadequate protein. The stimulating effect of including $15 \%$ of yeast in the diet was more marked in males than in females. This was of interest in view of the observation of Zucker \& Zucker (1944) that males require more protein than females. It has recently been suggested by Gray \& Addis (1948) that Zucker's curves may be used to test for abnormal growth of a rat colony. 'The results obtained in the present study confirm the value of the method for demonstrating normality of growth responses within a particular colony.

In all the curves of the groups other than those having yeast or stock diet, the points tend to fall very close to the straight line. For the females there are more irregularities, 
but the general trend of the curves encourages the view that the synthetic diets, even without the addition of liver extracts, are fairly satisfactory for normal growth.

The small increases in growth obtained when liver extract was added to the diets, as shown in Table $\mathrm{I}$, would seem to indicate that some essential factors were lacking in a purified diet supplemented with the known synthetic vitamins. The fact that liver extracts can provide a further growth stimulus with these diets seems to suggest that at least one factor may be the 'animal protein factor', zoopherin, described by Zucker, Zucker, Babcock \& Hollister (1948).

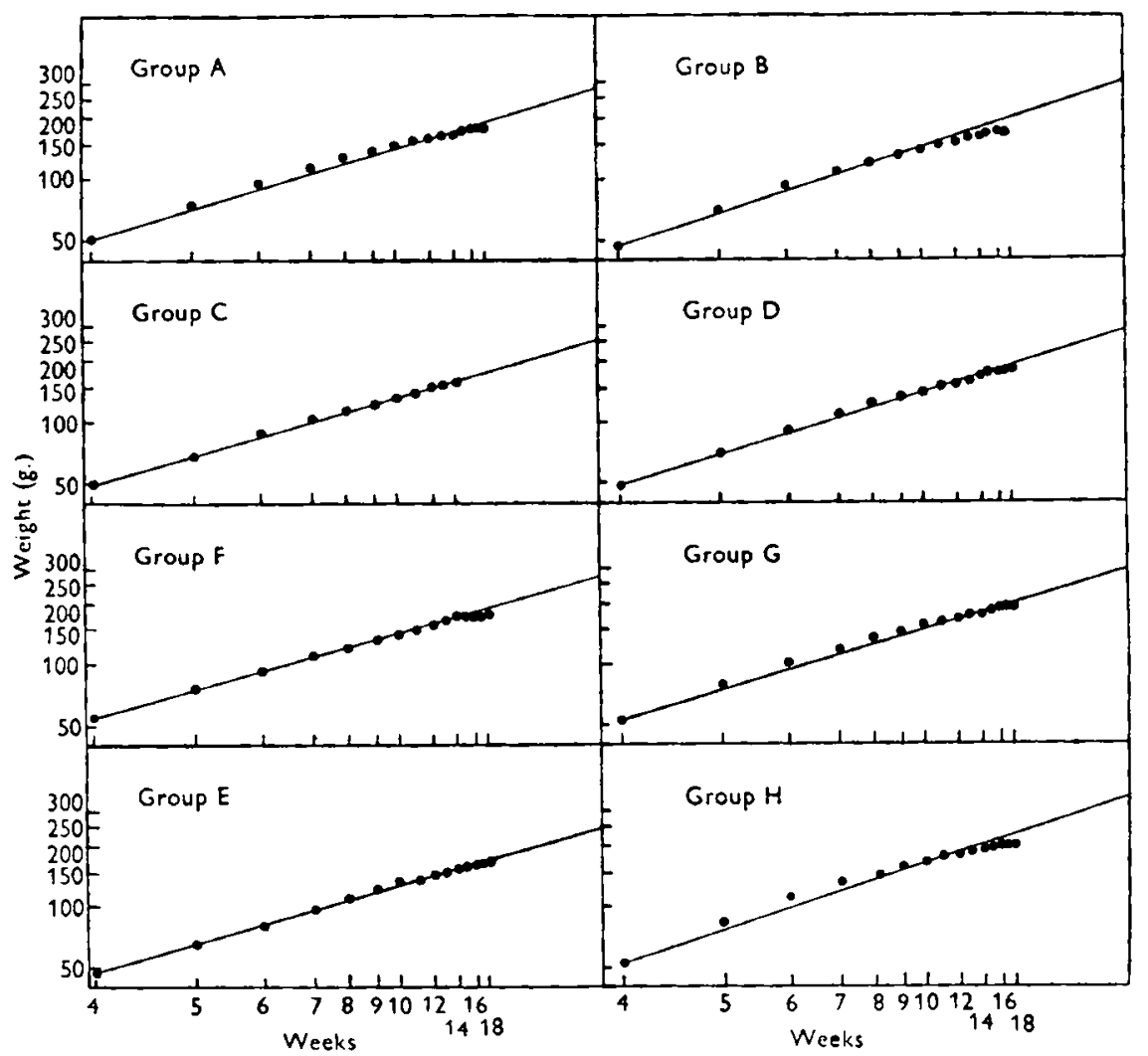

Fig. 3. Curves showing the relation between the reciprocal of the age in weeks and the logarithm of the mean body-weight in $\mathrm{g}$. of female rats on various diets.

\section{SUMMARY}

r. The rate of weight increase was studied in young rats receiving purified diets supplemented with synthetic vitamins with and without addition of liver extract.

2. Studies were made also with a diet containing $15 \%$ dried yeast and with a normal stock diet.

3. Addition of liver extract to a highly purified diet gave a slightly increased growth rate, but even with added liver extract the growth rates of animals having purified diets were not equal to those of rats on normal stock diet. 


\section{Alice M. Copping, Patricia J. Crowe and Vanda R. G. Pond i95 I}

4. The results are shown in curves of mean weight increase plotted directly against age and also according to Zucker's method for obtaining straight-line curves.

5. The results appear to confirm the observations of other workers that Zucker's curves provide valuable information about the normality of growth response within any given rat colony.

We acknowledge our indebtedness to Sir Charles Martin for many stimulating discussions that led to this investigation, and we thank him and Dame Harriette Chick for their continued helpful advice throughout the work. We thank also the Accessory Food Factors Committee of the Medical Research Council for samples of Labco and New Zealand casein, Messrs Glaxo Laboratories Ltd. for the liver extracts, and Messrs Roche Products Ltd. for making up special tocopherol solutions.

\section{REFERENCES}

Anderson, W. E. \& Smith, A. H. (1932). Amer. F. Physiol. roo, 511.

Dunn, M. S., Murphy, E. A. \& Rockland, L. B. (1947). Physiol. Rev. 27, 72.

Fridericia, L. S., Freudenthal, P., Gudjonnsson, S., Johansen, G. \& Schoubye, N.(1927). Y.Hyg., Camb., 27,70 .

Gray, H. \& Addis, T. (1948). Amer. F. Physiol. r53, 35.

Zucker, L., Hall, L., Young, M. \& Zucker, T. F. (1941 a). Growth, 5, 399.

Zucker, L., Hall, L., Young, M. \& Zucker, T. F. (1941 b). Growth, 5, 415.

Zucker, T. F., Hall, L., Young, M. \& Zucker, L. (r941 c). F. Nutrit. 22, 123.

Zucker, L. M., Zucker, T. F., Babcock, V. \& Hollister, P. (1948). Arch. Biochem. 16, I 5.

Zucker, T. F. \& Zucker, L. (1943). Industr. Engng Chem. (Industr. ed.), 35, 868.

Zucker, T. F. \& Zucker, L. (1944). Proc. Soc. exp. Biol., N.Y., 55, I36. 